\title{
〈Research Paper〉 \\ Electrochemical Study on Rhodamine 6G-Indole Based Dye for HOMO and LUMO Energy Levels
}

\author{
Hyungjoo Kim, Do-Hyun Lee ${ }^{1}$ and Young-A Son ${ }^{\dagger}$ \\ Department of Advanced Organic Materials and Textile System Engineering, \\ Chungnam National University, Daejeon, Korea \\ ${ }^{1}$ Korea Dyeing Technology Center, Daegu, Korea
}

(Received: February 26, 2013 / Revised: March 20, 2013 / Accepted: March 22, 2013)

\begin{abstract}
The energy levels are very important to investigate properties of organic dye materials. These values of energy levels can be calculated and compared with absorption spectra, cyclic voltammetric measurement and computer simulative calculation. In this study, absorption and emission changes were observed by complexation between rhodamine 6G based dye and mercury. This is related to spirolactam ring system of rhodamine $6 \mathrm{G}$ based dye. According to structural change of this dye, HOMO and LUMO energy levels were investigated and determined by their values with different approaches.
\end{abstract}

Keywords: HOMO, LUMO, Rhodamine 6G, absorption, cyclic voltammetry

\section{Introduction}

Rhodamine dyes have been received much attention and researched in various areas such as laser dyes, fluorescence standards, pigments, single-molecule imaging and imaging in living cells due to their excellent photostability and photophysical properties ${ }^{1)}$.

Rhodamines have interesting structural characteristics of their spriolactam ring system. The structure can be changed by the reaction of metal cations. When the ring system open by metal cations, specific absorption and emission change are being operated ${ }^{2)}$.

The energy levels such as HOMO and LUMO are related to the absorption character. In this regard, the energy levels were determined by molecular orbital and electron distribution ${ }^{3,4)}$. The studies of electro-chemistry, using HOMO and LUMO values, are useful for estimation of quantum chemistry calculation and redox/oxidation potential determination ${ }^{5,6)}$.

In this study, rhodamine $6 \mathrm{G}$ based dye material was investigated to calculate HOMO and LUMO energy values. Two different structures of this dye can be induced by the spirolactam ring system.

${ }^{\dagger}$ Corresponding author: Young-A Son (yason@cnu.ac.kr) Tel.: +82-42-821-6620 Fax.: +82-42-823-8870

(c) 2013 KSDF 1229-0033/2013-03/7-12
All computational calculations for the energy potential and the electron distribution of HOMO and LUMO states were simulated by the program named Material Studio 4.3 package program. In addition, the energy potentials of reduction and oxidation were determined by cyclic voltammetric mearsurement.

\section{Experimental}

\subsection{Rhodamine 6G Based Dye (Dye 1, Dye 1 $+\mathrm{Hg}^{2+}$ )}

The corresponding Rhodamine 6G dye was prepared and referred to the part of our previous work ${ }^{7)}$. The structure was shown in Figure 1. Rhodamine $6 \mathrm{G}$ hydrazide is prepared according to the literature method $^{8-10)}$. Rhodamine $6 \mathrm{G}(2 \mathrm{~g}, 4.18 \mathrm{mmol})$ was dissolved in $40 \mathrm{ml} \mathrm{MeOH}$. To the solution, hydrazine hydrate $(2.5 \mathrm{ml})$ was added dropwise, then the mixture was refluxed until the red color disappeared. After cooling to room temperature, the solution was poured into distilled water $(800 \mathrm{ml})$ and kept for 1day. Thereafter, the solid precipitate was filtered and dried in vacuum for 1day. Without further purification, the next step was preceded. Rhodamine 6G hydrazide $(0.428 \mathrm{~g}, 1.1 \mathrm{mmol})$ and indole-3-carboxaldehyde 


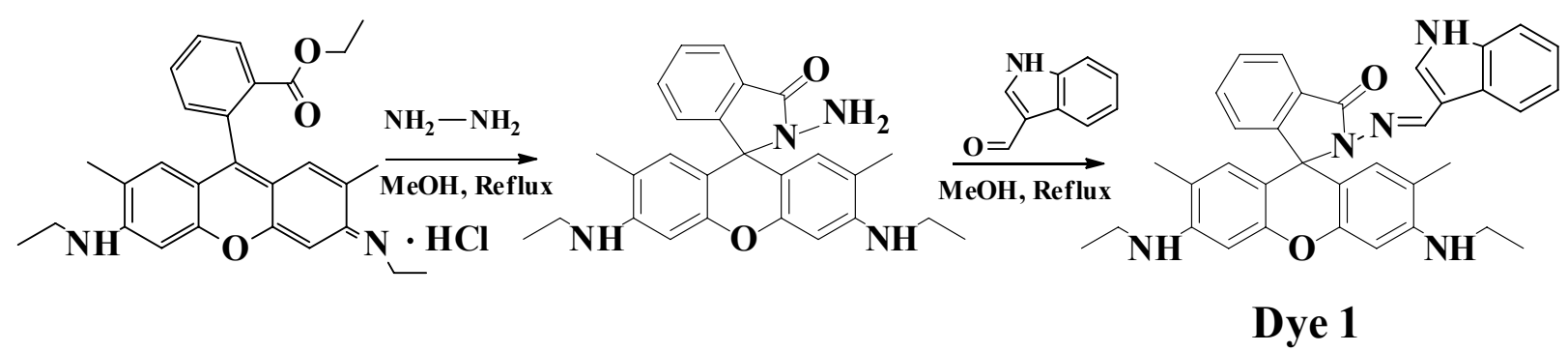

Scheme 1. The synthetic method for Dye $1^{7)}$

$(0.1596 \mathrm{~g}, 1.1 \mathrm{mmol})$ were refluxed in methanol with 3 drops of acetic acid. After 4hrs of stirring, white precipitates were obtained. These white solids were filtered off, washed with ethanol and dried in vaccum. The yield was 63\%. ${ }^{1} \mathrm{H}$ NMR $\left(\mathrm{CDCl}_{3}\right)$ : $9.21(\mathrm{~s}, 1 \mathrm{H}) ; 8.19(\mathrm{~s}, 1 \mathrm{H}) ; 8.02-7.99(\mathrm{~m}, 2 \mathrm{H}) ; 7.50$ $-7.48(\mathrm{~m}, 2 \mathrm{H}) ; 7.33-7.32(\mathrm{~d}, 1 \mathrm{H}) ; 7.20-7.12(\mathrm{~m}, 3 \mathrm{H})$; $6.43(\mathrm{~s}, 2 \mathrm{H}) ; 6.38-6.26(\mathrm{t}, 2 \mathrm{H}) ; 3.57-3.44(\mathrm{~d}, 2 \mathrm{H})$; 3.22-3.17 (m, 4H); 1.91-1.86 (d, 6H); 1.39- 1.25(m, $6 \mathrm{H})$. MS $m / z: 555\left(\mathrm{M}^{+}\right)$.

\subsection{Measurements}

The spectroscopic characteristics were examined and determined using Agilent 8453 UV-Vis spectrophotometer. The electro-chemistry properties of these dyes were examined with a Versa STAT 3 using a platinum wire served as a working electrode, and $\mathrm{Ag}$ $/ \mathrm{Ag}^{+}$electrode served as a reference electrode and a carbon served as a counter electrode. The scan rate was $50 \mathrm{mV} / \mathrm{s}$. The optimized geometry structure and molecular energy potentials were calculated with Materials studio 4.3.

\section{Results and Discussion}

We measured absorption and emission spectra of the prepared Rhodamine $6 \mathrm{G}$ derivative to investigate its optical properties, which can be changed by adding $\mathrm{Hg}^{2+}$ to dye 1 . Figure 1 showed that there is a specific change between dye 1 and dye $1 / \mathrm{Hg}^{2+}$ mixture in absorption spectrum. The new band centered at $525 \mathrm{~nm}$ was sharply formed. In naked eye, the color of dye solution was also changed from colorless to red. In addition, the fluorescence change was also observed in Figure 2.

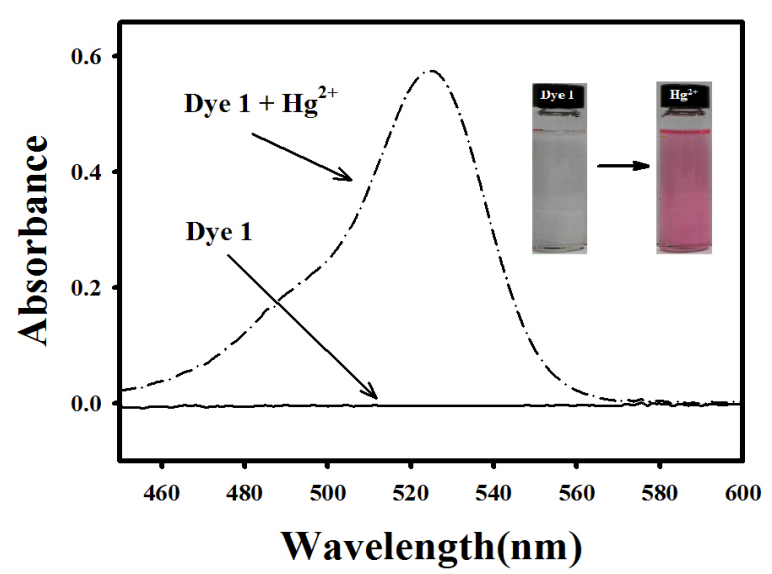

Figure 1. UV-Vis spectra of Dye $1(10 \mu \mathrm{M})$ upon addition of $\mathrm{Hg}^{2+}$ ions $(10 \mu \mathrm{M})$ in $\mathrm{MeCN}$. Inset: photographs of color change for dye 1 toward $\mathrm{Hg}^{2+}$ in $\mathrm{MeCN}$.

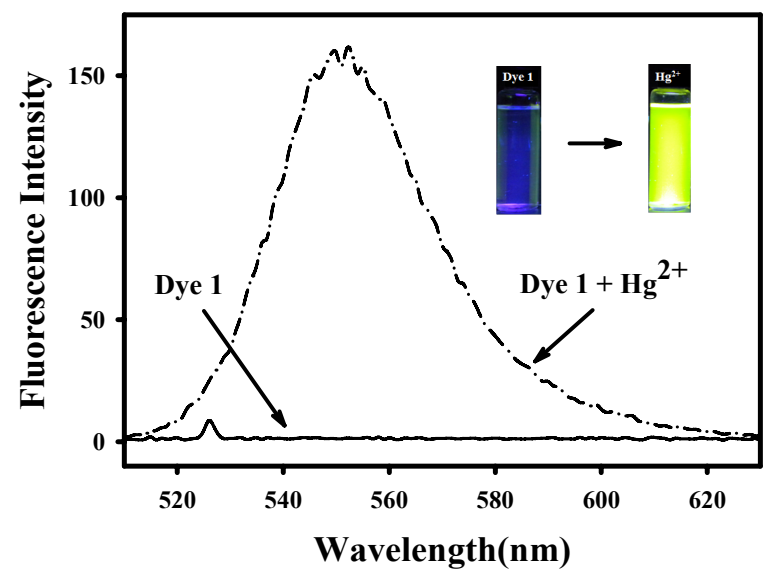

Figure 2. Fluorescence spectra of Dye $1(10 \mu \mathrm{M})$ upon addition of $\mathrm{Hg}^{2+}$ ions $(10 \mu \mathrm{M})$ in $\mathrm{MeCN}$. Inset: photographs of fluorescence change for dye 1 toward $\mathrm{Hg}^{2+}$ in $\mathrm{MeCN}$.

By addition of $\mathrm{Hg}^{2+}$ to dye 1 solution, new fluorescence band at $552 \mathrm{~nm}$ was appeared. The color change of fluorescent emission was demonstrated by the optical characteristics from non-fluorescence to green fluorescence. 
These absorption and fluorescence changes are attributed to the complex formation of dye 1 and $\mathrm{Hg}^{2+}$ complex. This phenomenon can be explained by spirolactam ring system of dye $1^{11,12)}$. The structure of dye 1 was changed in its form from closed to open ring by ligand formation bound by $\mathrm{Hg}^{2+}$ ion. This new open ring structure was proposed in scheme 2. This is based on Job's plot method, indicating 1:1 biding ratio between Dye 1 and $\mathrm{Hg}^{2+}$ as shown in Figure 3.

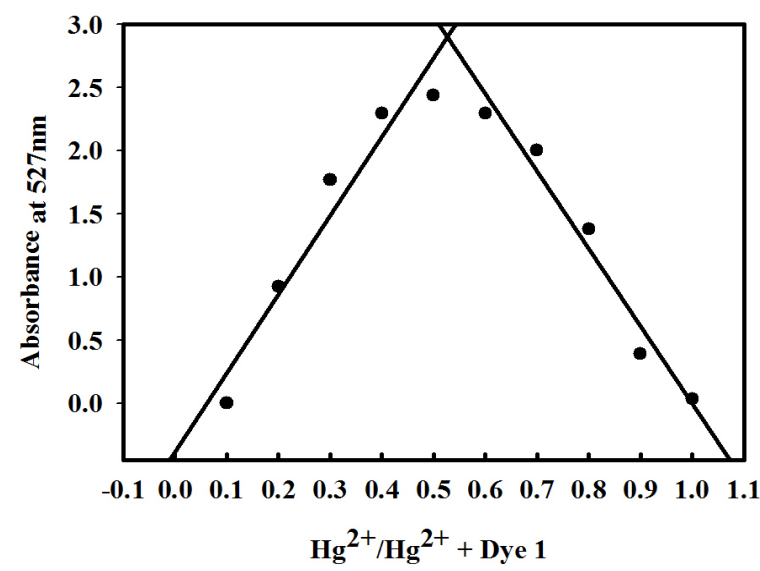

Figure 3. Job's plot method for Dye 1.

To investigate HOMO and LUMO energy levels between two different structures of dye 1 by changing the spirolactam ring system, we have measured UVVis absorption to obtain the band-gap energy potential, which show the energy level difference between HOMO and LUMO. As shown Figure 4 (a), (b), the band-gap energy potential values were calculated by spectroscopy, using $\mathrm{eV}=1240 / \lambda$ from absorption edge. The band-gaps of dye 1 and dye $1 / \mathrm{Hg}^{2+}$ were $2.27 \mathrm{eV}$ and $2.25 \mathrm{eV}$, respectively.
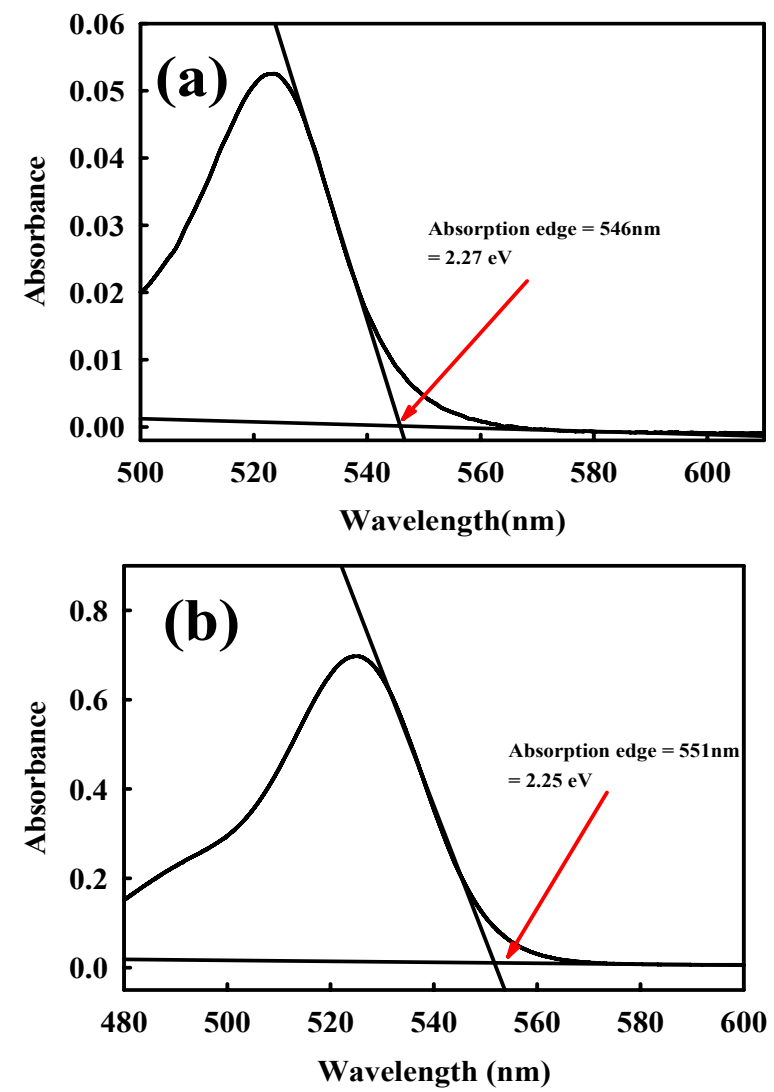

Figure 4. UV-Vis band-gap measurements : (a) Dye 1 $(100 \mu \mathrm{M})$, (b) Dye $1(50 \mu \mathrm{M})+\mathrm{Hg}^{2+}(50 \mu \mathrm{M})$ in $\mathrm{MeCN}$.

After mixing with dye 1 and $\mathrm{Hg}^{2+}$, the value was decreased about $0.02 \mathrm{eV}$.

Cyclic voltammograms were also investigated to calculate the HOMO and LUMO energy levels. Two factors of obtaining peak and onset potentials from spectra were considered for calculation of HOMO and LUMO energy levels. In Figure 5 (a) and (b), Oxidation peak and onset potentials were clearly observed. These spectra showed the different potential positions, indicating that different structures may exist, showing different electrochemical behaviors.

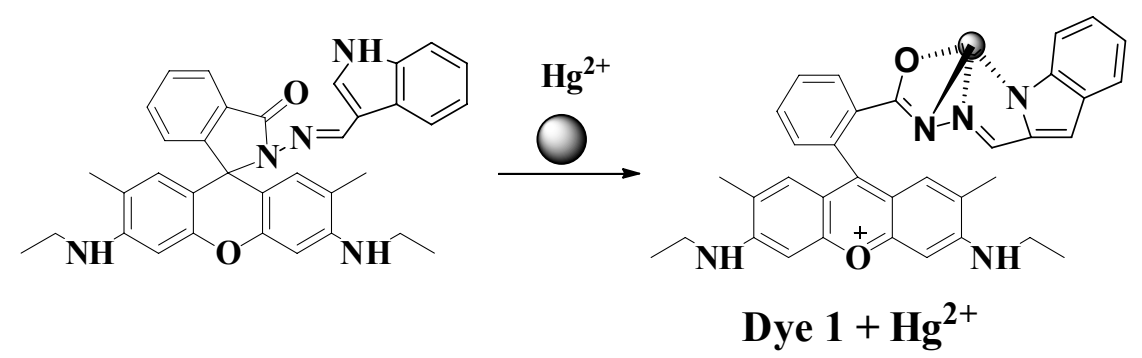

Scheme 2. The proposed mechanism of Dye $1+\mathrm{Hg}^{2+}$ 
HOMO (or LUMO) $(\mathrm{eV})=$

$-4.8-\left(\mathrm{E}_{\text {peak }} /\right.$ onset $-\mathrm{E}_{1} / 2$ (Ferrocence) $)$

The following peak potential and onset potential in Figure 5 were used for HOMO and LUMO energy level calculations with equation $(1)^{13-15)}$. E $1 / 2$ (Ferrocence) values of $0.42 \mathrm{~V}$ were applied in the equation (1). Oxidation values of onset and peak potentials for Dye 1 were obtained as $-4.94 \mathrm{eV}$ and $-5.15 \mathrm{eV}$, respectively.

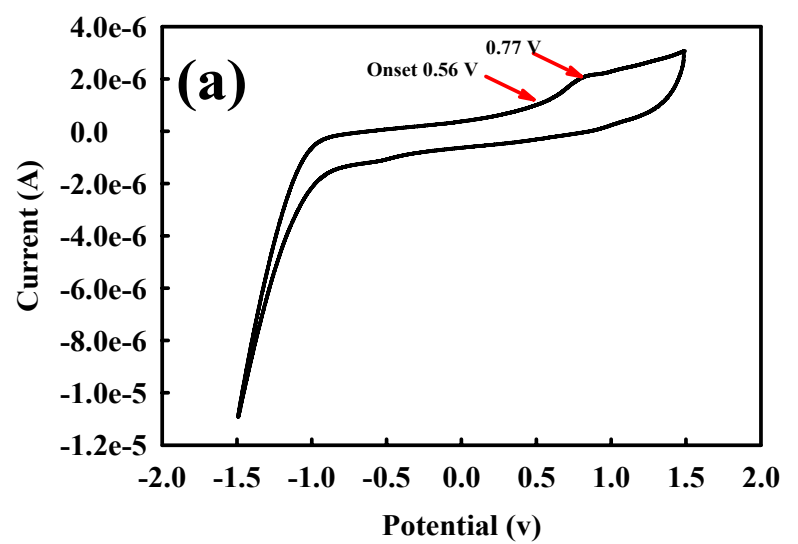

Figure 5. Cyclic voltammograms : (a) Dye $1 \quad(100 \mu \mathrm{M})$, lammonium perchlorate was added for electrolyte.
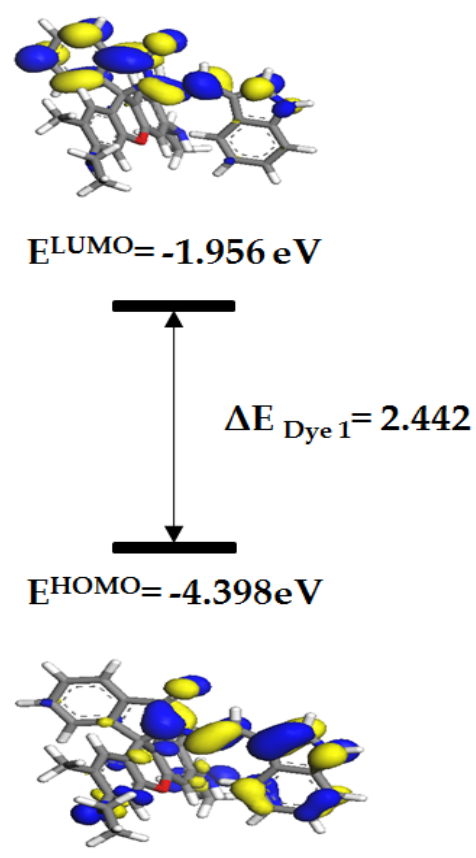

Figure 6. HOMO/LUMO energy levels and electron distributions for Dye 1 and Dye $1+\mathrm{Hg}^{2+}$.
The same values of Dye $1 / \mathrm{Hg}^{2+}$ were also obtained as each $-5.21 \mathrm{eV}$ and $-5.36 \mathrm{eV}$. These are related to HOMO energy levels. Through the results, there are little differences between the calculated values from each peak and onset potentials. However, these two values are useful for determination and analysis of electrochemical properties for Dye 1 and Dye $1 / \mathrm{Hg}^{2+}$. In addition, HOMO and LUMO energy levels and electron distributions of Dye 1 and Dye $1 / \mathrm{Hg}^{2+}$ were computationally simulated as shown in Figure 6 .

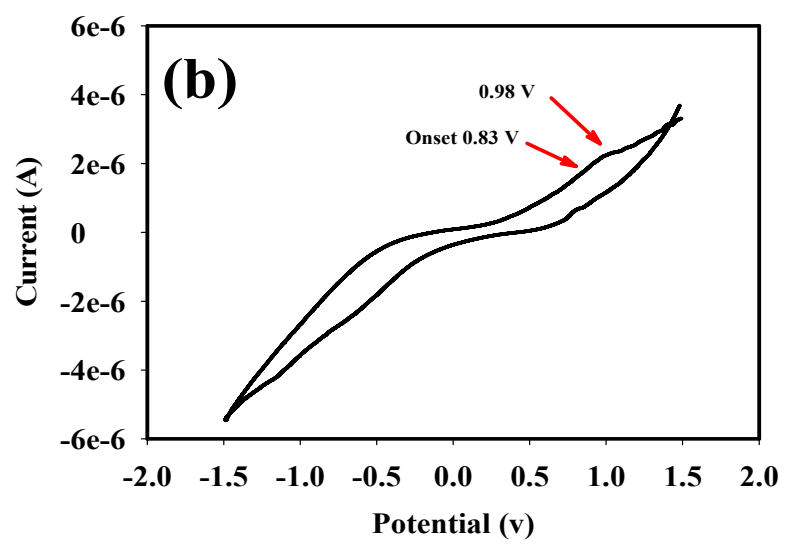

(b) Dye $1(500 \mu \mathrm{M})+\mathrm{Hg}^{2+}(500 \mu \mathrm{M})$ in $\mathrm{MeCN}$. Tetrabuty-

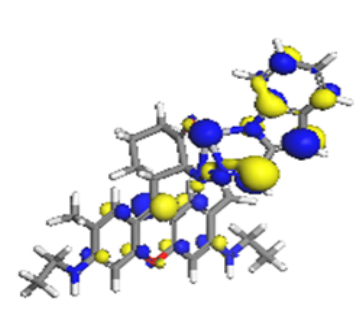

$E^{L U M O}=-2.573 e V$

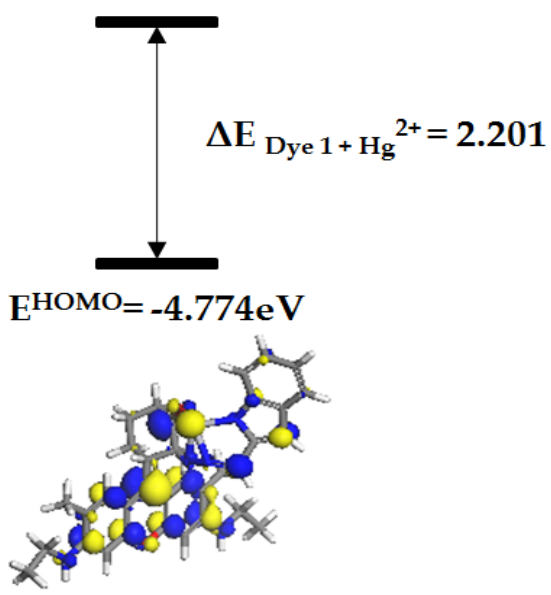


Table 1. HOMO/LUMO and band-gap energy potential

\begin{tabular}{cccccccccc}
\hline Sample & \multicolumn{3}{c}{ Onset $(\mathbf{e V})$} & & & Peak (eV) & & \multicolumn{2}{c}{ Computational Calculations (eV) } \\
\hline \hline Type & HOMO & LUMO & $\triangle \mathrm{E}$ & HOMO & LUMO & $\triangle \mathrm{E}$ & HOMO & LUMO & $\triangle \mathrm{E}$ \\
Dye 1 & -4.94 & -2.67 & 2.27 & -5.15 & -2.88 & 2.27 & -4.398 & -1.956 & 2.442 \\
Dye $1+\mathrm{Hg}^{2+}$ & -5.21 & -2.96 & 2.25 & -5.36 & -3.11 & 2.25 & -4.774 & -2.573 & 2.201 \\
\hline
\end{tabular}

The dye 1 has been simulated with Materials Studio 4.3 suite of program which is the quantum mechanical code using density functional theory.

Perdew-Burke-Ernzerhof function of generalized gradient approximation level with double numeric polarization bases set was used to calculate the energy level of the frontier molecular orbits ${ }^{16-18)}$. In Dye 1, electron localization was moved from xanthine and indole-3- carboxaldehyde to a unit of rhodamine $6 \mathrm{G}$.

The dye $1 / \mathrm{Hg}^{2+}$ showed different electron denstity localization compared with Dye 1. In Indole-3-carboxaldehyde part, considerable electron localization was induced in HOMO and LUMO states. There was no specific change in xanthene.

Based on the above results, computational calculated and electrochemically determined levels were energy levels were compared and shown in Table 1. The results showed that the values of onset potential are closer than the obtained values from peak potential compared with computational calculations. This may propose that onset potential calculation is more accurate than peak potential calculation.

\section{Conclusions}

In this study, we investigated the electrochemical study for two different structures of rhodamine $6 \mathrm{G}$ based dye derivative. These structures were formed by the spirolactam ring close-open system.

The electrochemical properties and computational calculations were examined and compared for obtaining $\mathrm{HOMO} / \mathrm{LUMO}$ energy levels. According to the change of structure for dye 1, these energy levels were changed, indicating that molecular structure can affect to HOMO/LUMO energy levels.
It is also proposed that onset potential calculation is more accurate than peak potential calculation and its effective approaches were compared to consider more detailed characteristics of the designed molecules.

\section{Acknowledgment}

This research was supported by a grant from the fundamental R\&D program for core technology funded by the ministry of knowledge economy, Republic of Korea.

\section{References}

1. M. Beija, C. A. M. Afonso, and J. M. G. Martinho, Synthesis and Applications of Rhodamine Derivatives as Fluorescent Probes, Chem. Soc. Rev., 38(8), 2410(2009).

2. X. Chen, T. Pradhan, F. Wang, J. S. Kim, and J. Yoon, Fluorescent Chemosensors Based on Spiroring -Opening of Xanthenes and Related Derivatives, Chem. Rev., 112(3), 1910(2012).

3. G. B. Ferreira, E. Hollauer, N. M. Comerlato, and J. Wardell, An Experimental and Theoretical Study of the Electronic Spectra of Tetraethylammonium [bis(1,-dthiole-2-thione-45-dithoato)M(III)] and Tetraethylammonium [bis(1,3-dithiole-2-e-4,5dithilato)M(III)] $(\mathrm{M}=\mathrm{Sb}$ or $\mathrm{Bi})$, Spectrochim. Acta Part A, 71(1), 215(008).

4. C. N. Ramachadran, D. Roy, and N. Sathyamurthy, Host-Guest Interaction in Endohedral Fullerenes, Chem. Physic. Lett., 461, 87(2008).

5. I. Losito, F. Palmisano, and P. G. Zambonin, O Phenylenediamine Electropolymerization by Cyclic Voltammetry Combined Eectrospray Ioization-Ion Tap Mass Spectrometry, Anal. Chem., 75(19), 4988(2003). 
6. C. J. Tonzola, M. M. Alam, W. Kainsky, and S. A. Jenekhe, New n-Type Organic Semiconductors: Synthesis, Single Crystal Structures, Cyclic Voltammetry, Photophysics, Electron Transport, and Electroluminescence of Series of Diphenylanthrazolines, J. Am. Chem. Soc., 125(44), 13548 (2003).

7. H. Kim, S. H. Kim, D. H. Lee, and Y. A. Son, Design and Synthesis of Novel Chemosensor Based on Rhodamine 6G Monitoring Heavy Metal Ions, Supramol. Chem., 25(2), 87(2013).

8. S. P. Wu, T. H. Wang, and S. R. Liu, A Highly Selective Turn-On Fluorescent Chemosensor for Copper(II) Ion, Tetrahedron, 66(51), 9655(2010).

9. M. Beija, C. A. Afonso, and J. M. Martinho, Synthesis and Applications of Rhodamine Derivatives as Fluorescent Probes, Chem. Soc. Rev., 38(8), 2410(2009).

10. W. Y. Kang and J. S. Park, Preparation of Polymeric Metal Complex Containing Azo Dye Rotaxane, Textile Coloration and Finishing(J. Korean Soc. Dye. and Finish.), 23(3), 163(2011).

11. L. Huang, X. Wang, G. Xie, P. Xi, Z. Li, M. Xu, Y. Wu, D. Bai, and Z. Zeng, A New Rhodamine -Based Chemosensor $\mathrm{Cu}^{2+}$ and The Study of Its Behaviour in Living Cells, Dalton Trans., 39(34), 7894(2010).

12. D. Wu, W. Huang, C. Duan, Z. Lin, and Q. Meng,
Highly Sensitive Fluorescent Probe or Selective Detection of $\mathrm{Hg}^{2+}$ in DMF Aqueous Media, Inorg. Chem., 46(5), 1538(2007).

13. H. S. Lee and J. H. Kim, Measurement of Phy-sical Properties of Conducting Polymers, Polymer Sci. Technol., 18, 488(2007).

14. Y. S. Kim, J. I. Shin, S. Y. Park, K. Jun, and Y. A. Son, Electrochemical Studies on Heptamethine Cyanine Dyes, Textile Coloration and Finishing(J. Korean Soc. Dye. and Finish.), 21(5), 35(2009).

15. Y. S. Kim, S. H. Kim, T. K. Kim, and Y. A. Son, Characteristics of HOMO and LUMO Potentials by Altering Substituents: Computational and Electrochemical Determination, Textile Coloration and Finishing(J. Korean Soc. Dye. and Finish.), 20 (5), 41(2008).

16. B. Delley, An All-Electron Numerical Method for Solving The Local Density Functional for Polyatomic Molecules, J. Chem. Phys., 92(1), 508(1990).

17. B. Delley, From Molecules to Solids with the DMol $^{3}$ Approach, J. Chem. Phys., 113(18), 7756 (2000).

18. A. D. Boese and N. C. Handy, A New Parametrization of Exchange-Correlation Generalized Gradient Approximation Functionals, J. Chem. Phys., 114(13), 5497(2001). 